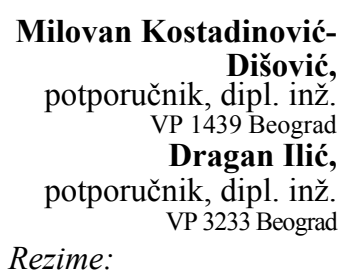

Rezime:

\section{SIMULACIJA RADA OPTIČKE MREŽE POMOĆU SIMULATORA NS-2}

UDC: 621.39

Optički multipleks zasnovan na talasnoj dužini nosioca OWDM je tehnologija mreža identifikovana kao odgovarajuća buduća širokopojasna mrežna okruženja, sa dokazanim mogućnostima u pogledu odgovora na povećane zahteve navedenih mreža i kratkom vremenu za uspostavljanje komunikacija. Buduće optičke širokopojasne mreže $O W A N^{2}$ zahtevaju stvaranje odgovarajućih mrežnih protokola i algoritama koji treba da odgovore na promenljive operativne zahteve.

Ključne reči: višetalasni dupleks link, simulacija, srednja brzina dolazećeg saobraćaja, srednje vreme zadržavanja saobraćaja, komutacija fotonskog paketskog prenosa, višeprotokolsko lambda komutiranje, kružna komutacija.

\title{
SIMULATION OF OPTICAL NETWORK OPERATION USING
} SIMULATOR NS-2

Summary:

Optical wavelenght division multiplexing $\left(W D M^{3}\right)$ networking technology has been identified as a suitable candidate for future wide area network $\left(W A N^{4}\right)$ enviroments, due ti its potential ability to meet rising demands of high bandwith and low latency communication. Networking protocols and algorithms are being developed to meet the changing operational requirements in future optical WANs (OWAN).

Key words: duplex fiberlink, simulation, mean session arrival rate, mean session holding rate, photonic packet switching, multi-protocol lambda switching, circuit switching.

\section{Uvod}

Imajući u vidu da je simulacija postala neophodan alat $u$ opštem ispitivanju mreža, kada istraživači mogu brzo i bez troškova da procene karakteristike novih protokola, postavlja se pitanje same suštine jednog ovakvog poduhvata. Glavni problemi pri izradi jednog simulatora jesu, pre svega, uniformno mrežno okruženje, kao i razmatranje samog dizajna simulatora. Naime, problem uniformnog

\footnotetext{
OWDM - Optical Wavelength Division Multiplex Multiplex zasnovan na talasanoj dužini nosioca.

OWAN - Optical Wide Area Network.
}

okruženja odnosi se na samu srž rada simulatora koja se u ovom slučaju odnosi na mrežni sloj (rutiranje, dodela talasnih dužina, itd.).

Skoro ceo prioritetni deo ovakvog gledišta WDM mreža baziran je na simulacionim modelima dizajniranim specifično za taj problem. Znajući da postoje različite simulacione platforme i pretpostavke, teško je iskoristiti postojeće protokole i uporediti rezultate pod običnim simulacionim okruženjem. Univerzalno

\footnotetext{
${ }^{3}$ WDM - Wavelength Division Multiplex.

${ }^{4}$ WAN - Wide Area Network.
} 
simulaciono mrežno okruženje koje bi omogućilo upoređivanje ključnih karakteristika WDM mreža postalo je neophodno. To bi obezbedilo razvojnim timovima WDM mreža okvir za rad i laku implementaciju novih protokola i karakteristika WDM mreža koje se nalaze u ekspanziji, i lakše upoređivanje dobijenih rezultata, što uključuje ponovno korišćenje postojećih protokola i komponenti simulacija. Što se tiče dizajna simulatora treba istaći da na tržištu postoji veliki broj simulatora, kako besplatnih, tako i komercijalnih, specifično urađenih, za određene namene [1]. Okosnicu simulatora NS-2, po ovom pitanju, predstavlja $\mathrm{C}++$ jezik u saradnji sa OTcl ${ }^{5}$. Naime, samu funkcionalnost elemenata u svakoj vrsti simulacije koju podržava NS-2 obezbeđuje $\mathrm{C}++$ programski jezik, dok povezivanje elemenata i definisanje same topologije mreže mora da se izvede pomoću jezika OTcl.

\section{Arhitektura komutacije optičkog simulatora}

Arhitektura zastupljena u optičkom simulatoru dizajnirana je tako da se prilagodi specifičnim karakteristikama potrebnim simulaciji u WDM mreži. Na osnovu toga treba istaći da optički simulator, zasnovan na NS-2 platformi, radi sa fizičkom i logičkom topologijom mreže.

Elementi koji se javljaju na fizičkom planu mreže su komutacioni čvorovi sa optičkom komutacijom, kao i linkovi sa višestrukim talasnim dužinama. Znači, na ovom nivou posmatraju se upravo ele-

${ }^{5}$ Otcl - Object Technical Language - programski jezik koji je razvijen u SAD. menti od kojih esencijalno zavisi mehanizam putanje paketa kroz simuliranu mrežu. Logički sloj obuhvata module rutiranih putanja i module za dodeljivanje talasnih dužina $\mathrm{WA}^{6}$, koji zajedno stvaraju i održavaju virtuelnu topologiju mreže. Na ovom nivou ostvaruje se uspostavljena optička putanja, kao i centralizovana višekanalna struktura odgovorna za ukupan uvid o ostvarenim putanjama $i$ iskorišćenim talasnim dužinama.

Verzija korišćena u ovom radu podržava kružnu komutaciju, dok su implementacija komutacije velike količine saobraćaja $\mathrm{OBS}^{7}$, zatim komutacije fotonskog paketskog prenosa, kao i višeprotokolskog lambda komutiranja predviđeni za neki budući rad. Uvođenjem navedenih tehnologija znatno će se promeniti sama struktura rada optičke mreže, ako se ima u vidu kakve prednosti one donose.

\section{Komponente optičkog simulatora NS-2 i iniciranje saobraćaja}

Vrlo bitno pitanje predstavlja uvođenje novih komponenti u postojeći mrežni simulator NS-2, koje treba da obezbede odgovarajući rad i simulaciju optičkih komponenti, kao i njihovu međusobnu interakciju. Optički komutacioni čvor, višetalasni linkovi, moduli za rutiranje i modul za dodelu talasnih dužina implementirani su u simulator NS-2 kao posebne komponente koje se uvode posebnim naredbama OTcl jezika: WDMNode, duplex - FiberLink, RouteLogic/Wavelength i WAssignLogic.

\footnotetext{
${ }^{6}$ WA - Wavelength Assignment - dodeljivanje tala-
snih dužina.

OBS - Optical Burst Switching - optička komutacija
} 
WDMNode predstavlja optički čvor koji je izveden iz postojeće definicije čvora, prisutne u samom mrežnom simulatoru NS-2. U njemu se vrše dve vrste klasifikacije po pitanju ulaza (porta) i po pitanju optičke putanje. Klasifikator portova demultipleksira i prenosi pakete do njihovih odredišta, koji su objekti posebne klase unutar simulatora po imenu Application/SessionTraffic. Klasifikator putanja sarađuje sa WAssignLogic komponentom logike, kako bi uspostavio putanje za dolazni saobraćaj i dopunjuje novim informacijama trenutno stanje virtuelne topologije. Ovaj klasifikator, kod izvornog čvora, uvek pokušava da reši zahteve za putanje za svoj generisani saobraćaj ka WAssignLogic komponenti.

Klasični dupleks link, prisutan u simulatoru NS-2, dopunjen je kako bi se formirao višetalasni dupleks link označen kao duplex-FiberLink [3]. Naravno, on ima određene dodatne osobine koje karakterišu upravo njegovu namenu pri optičkoj komunikaciji, kao što su broj talasnih dužina i prošireni opseg, što je, pak, iskorišćeno za modelovanje karakteristika optičkih linkova. Druga bitna razlika u odnosu na postojeće klasične linkove prisutne u simulatoru NS-2 jeste odsutnost komponente čekanja u višetalasnom linku zbog činjenice da se takva osobina ne sme očekivati u modernim optičkim vezama.

Modul odgovoran za procenu pri dodeli talasnih dužina, uspostavljanje veza i pravljenje virtuelne topologije označen je kao WA modul u hijerahijskom konceptu optičkog simulatora NS-2. Ovaj modul sadrži logiku koja čuva informacije potrebne pri izračunavanju i dodele talasnih dužina. Takođe, moguće je implementirati i nove algoritme za dodelu talasnih dužina upotrebom prenosnih klasa objekta WAssignLogic.

Modul rutiranja je, sa određenim izmenama, prenesen iz klasičnog simulatora NS-2 zbog činjenice da su algoritmi rutiranja postojećih mreža slični, po funkcionalnosti, sa rutiranjem u WDM mrežama. Kao početni algoritam rutiranja, optički simulator koristi algoritam sa fiksnom - alternativnom i najkraćom putanjom (engl. fixed-alternate shortest path).

Generisanje saobraćaja ima značajnu ulogu u simulaciji, radi pravilnog shvatanja performansi sistema. U simulatoru NS-2, postojeći izvori saobraćaja, kao što su $\mathrm{CBR}^{8}$, Exponential i Pareto, dizajnirani su tako da su sposobni za simulacije paketskog prenosa. Prema tome, upravo ovde su i napravljene najveće izmene, kako bi se izašlo u susret komutaciji kola prisutnoj u optičkoj komunikaciji, na ovom nivou razvoja simulatora.

Da bismo opisali saobraćaj u mreži, moramo se upoznati sa dva važna parametra: srednjom brzinom dolazećeg saobraćaja $(\mathrm{MSAR})^{9}$ i srednjim vremenom zadržavanja saobraćaja $(\mathrm{MSHT})^{10}$. Oba parametra mere se saobraćajem između izvora i odredišta. Proizvod MSAR i MSHT predstavlja saobraćaj meren u erlanzima i za svaki prenos - distribucija dolaznih paketa je uzeta kao CBR, Exponential ili Pareto. Takođe, postojeći alat za generisanje scenarija prisutan u simulatoru NS-2 proširen je dodacima za generisanje topologije i saobraćaja. Narav-

\footnotetext{
${ }^{8} \mathrm{CBR}-$ Constant Bit Rate.

${ }^{9}$ MSAR - Mean Session Arrival Rate - srednja brzina dolazećeg saobraćaja.

MSHT - Mean Session Holding Time - srednje vreme zadržavanja saobraćaja.
} 
no, u svakom trenutku moguće je izgenerisati željenu topologiju i karakteristike mreže prema nekom specifičnom zahtevu, a moguće je obaviti i veliki broj merenja na nekom slučajno uzetom uzorku i primeru mreže.

\section{Vizuelni prikaz i simulacija u simulatoru NS-2}

Za vizuelno prikazivanje rada simulacije optički simulator koristi već postojeći alat implementiran u simulatoru NS-2, označen kao nam. nam, koji čita izlazni rezultat koji je generisao simulator NS-2, i koji daje vizuelni prikaz. Prikaz protoka je uobičajen i predstavljen paketskom animacijom. Da bi se podržao rad WDM mreža, ekstenzije uvedene u nam alatu daju prikaz dva stanja: posmatranje događaja i statistiku virtuelne topologije.

Posmatranje događaja uvedeno je radi prikazivanja paketskog prenosa $\mathrm{u}$ virtuelnoj tehnologiji, kao što je, na primer, zahtev za prenošenje dolaznog sao- braćaja. Posmatranje se može aktivirati u novom, odvojenom prozoru ili u okviru glavnog prozora. Klikom na određeni događaj u mreži ponavljanje tog događaja se momentalno prikazuje tamo gde se pojavio. To omogućuje da se detektuju i ispitaju zanimljivi momenti. Izgled klasičnog primera topologije mreže prikazan je na slici 1 .

Primer simulacije koji je urađen korišćenjem optičkog simulatora NS-2 ima niz pogodnosti, i pored činjenice da nije urađen kao primer jedne konkretne i primenjene optičke mreže, što bi predstavljalo pravi smisao jednog ovakvog rada i izazov za autore i njihov budući rad. Kao i većina simulacija koje funkcionišu pod ovim linux baziranim simulatorom, i ova se simulacija sastoji od dva bitna dela [4].

U jednom je moguće definisati i menjati čitav niz različitih parametara bitnih za rad simulacije i krajnje rezultate, dok se u drugom pozivaju različite procedure kojima se kontroliše rad i simulacija definisane mreže. Već je istaknuto da je

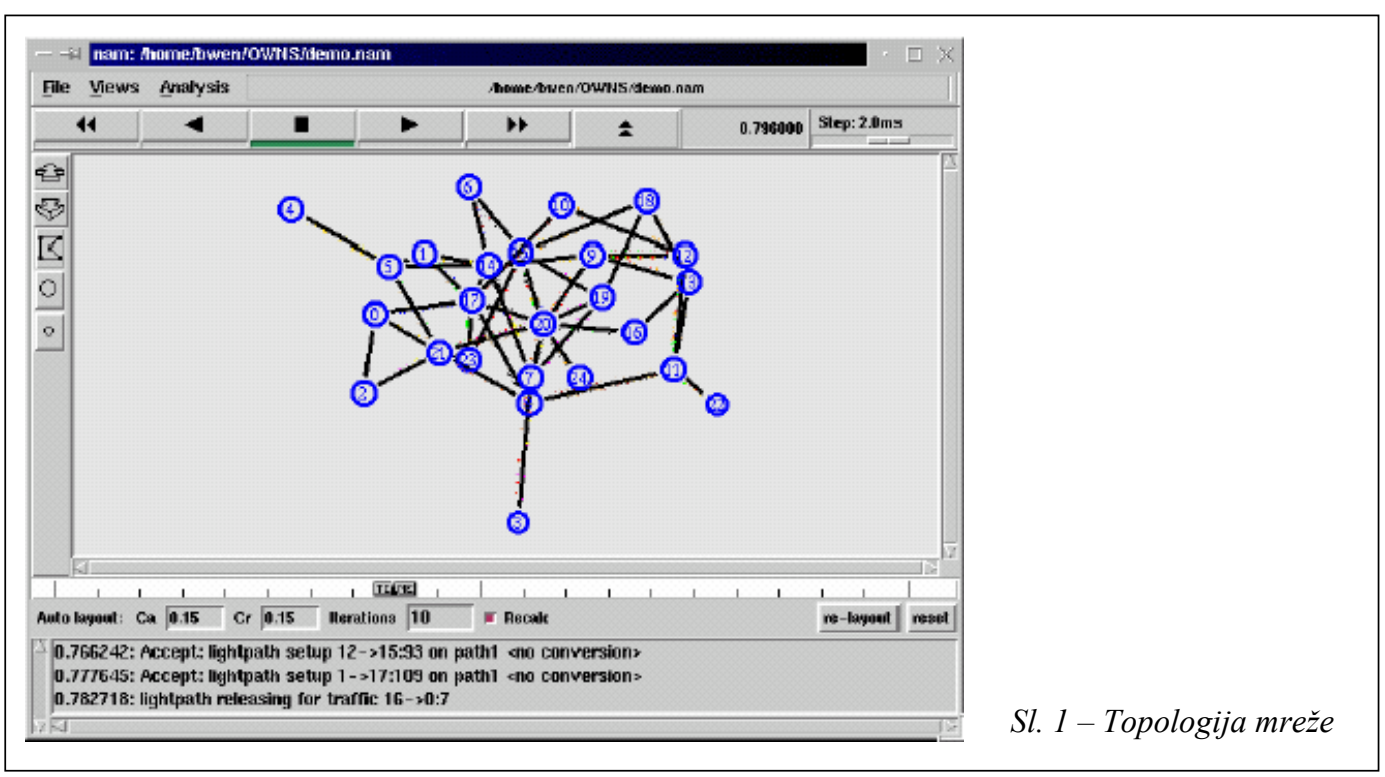


sam simulator NS-2 baziran na OTcl programskom jeziku, koji svoju podršku zatim nalazi u $\mathrm{C}++$ okruženju, na kojem je i zasnovan ovaj linux mrežni simulator, tako da je neophodno poznavanje ovog jezika za pisanje programskog koda.

Protokol koji je implementiran u optički deo ovog simulatora, a koji se odnosi na proceduru dodele talasnih dužina, označen je kao FirstFit, dok je protokol odgovoran za rutiranje WDMStatic. Ova dva protokola rešavaju najbitniji problem po pitanju rutiranja pri prenosu u optičkom domenu RWA ${ }^{11}$. Zbog činjenice da je moguće definisati čitav niz parametara po pitanju izgleda same mreže u ovoj simulaciji (broj čvorova, propusni opseg linka, broj talasnih dužina po svakom lin$\mathrm{ku}$ ), topologija mreže se proizvoljno bira pomoću slučajnog uzorka.

Zahvaljujući promeni parametara moguće je ispitivati različita ponašanja u mreži. Naravno, ostavljena je mogućnost definisanja sasvim konkretne i unapred definisane mreže, pomoću odgovarajućih naredbi implementiranih u optički simulator. Kao krajnji rezultat dobija se izlazni fajl u kojem se nalaze izračunate vrednosti određene simulacije, a koje se odnose na srednje kašnjenje paketa u mreži, verovatnoću blokiranja na pojedinačnom linku, iskorišćenost linka, kao i srednji broj hopova u mreži. Izmenama određenih parametara mogu se dobiti različite krive zavisnosti ispitivane mreže, od kojih su neke date na sledećim slikama. Krive prikazane na slikama dobijene su korišćenjem klasičnih statističkih alata za obradu podataka, pri čemu su podaci uzeti iz rezultujućeg fajla simulacije.

"I RWA - Routing Wavelengt Assignment - rutiranje u optičkom domenu.
Na slikama 2 i 3 dati su prikazi za po dve putanje: putanja 1 i putanja 2 . $\mathrm{Za}$ obe putanje dati su prikazi za 48 i 64 talasne dužine.

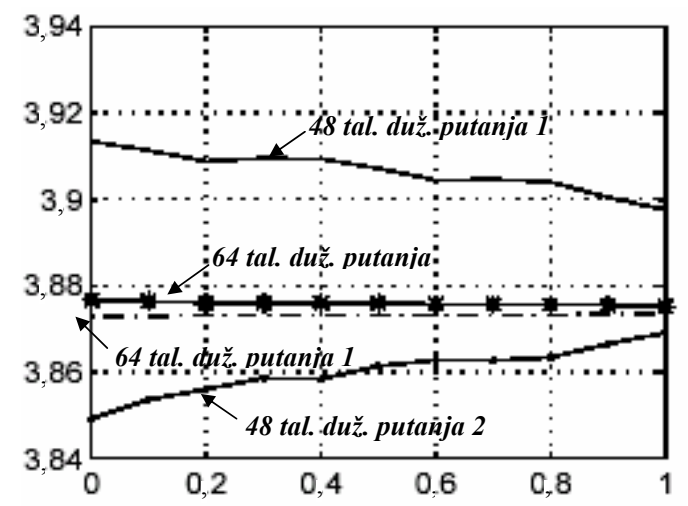

Sl. 2 - Zavisnost srednjeg broja hopova u mreži od faktora konverzije talasne dužine

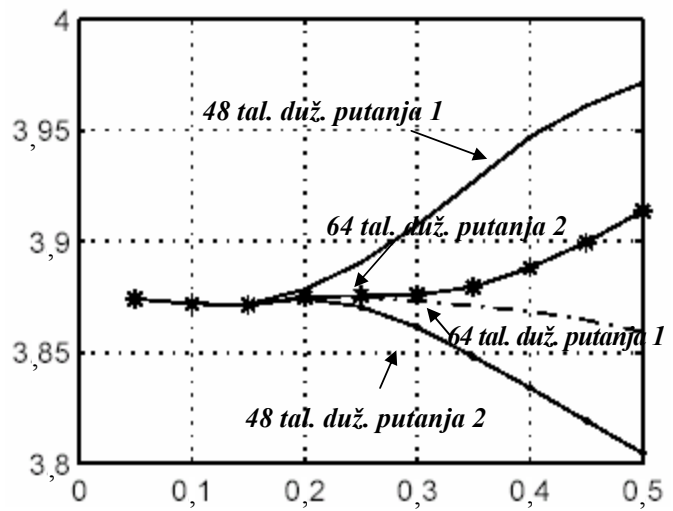

Sl. 3 - Zavisnost srednjeg broja hopova u mreži od saobraćaja koji se prenosi

Mogućnost konverzije talasnih dužina u mreži primenjena je uz korišćenje modela konverzije talasne dužine, izražena u procentima (engl. Sparse wavelength conversion), i parametar koji predstavlja procenat čvorova u mreži koji imaju mogućnost konverzije talasne dužine, a uveden je u simulaciju pod ovim imenom i tokom simulacije se može menjati. 


\section{Zaključak}

Imajući u vidu kakve prednosti donosi postojanje jedne ovakve infrastrukture, $\mathrm{s}$ razlogom se mogu navesti mnogobrojne pogodnosti jednog detaljnog simuliranog procesa koji treba sprovesti, kako bi se u potpunosti mogle sagledati mogućnosti optičke mreže, čak i pre same njene izgradnje. Naravno, gusti multipleks, zasnovan na bazi talasnih dužina (DWDM - Dense Wavelength Division Multiplex), već je sada realna potreba, pa treba raditi na implementaciji, kako simulacije, tako i same mreže.

Konačni cilj svakako predstavlja komutacija i rutiranje u samom i isključivom optičkom domenu pomoću uređaja tipa $\mathrm{OSR}^{12}$, koji predstavlja optički ruter, što je sigurno izazov za budućnost i sam mrežni simulator NS-2, pošto se planira uvođenje modula za podršku rada ovakvog uređaja u budućim rešenjima ovog softverskog alata.

Budući radovi u ovoj oblasti zahtevaju korišćenje već postojećih rezultata, na primeru primene jedne konkretne optičke mreže, sa navedenim načinom prenosa informacija, čija će se implementacija zahtevati i u sistemu veza Vojske Srbije.

Literatura:

[1] http://www.isi.edu

[2] Somani, A. K.: Survivability and traffic grooming in WDM optical networks, Cambridge University Press 2005.

[3] Green, P.: Progress in optical networking, IEEE Communications Magazine, Jan. 2001.

[4] Fall, K., Varadhan, K.: The ns manual, VINT Project, 2001.

${ }^{12}$ OSR - Optical Switching Router - optički ruter. 